\title{
Improving the technology of operating electric locomotives using electric power storage device
}

\author{
Kirill Domanov ${ }^{1, *}$, Andrei Shatohin ${ }^{1}$, Vladislav Nezevak ${ }^{1}$, Vasily Cheremisin ${ }^{1}$ \\ ${ }^{1}$ Omsk State Transport University, 644046, Marx av., 35, Omsk, Russia
}

\begin{abstract}
The article discussed the questions of the railway transportation organization along the transport corridors passing through the territory of Russia using the innovative locomotives of new generation with the polygon's structure of the transportation process' organization. There was carried out an analysis of the railway car standing at the docking stations of the single-phase alternating and direct current. The results of simulation modeling of the transportation process on the railway sections, which have a docking station, are given. There are shown the positive effects of the perfection of the polygon's exploitation technology of the locomotive fleet due to introduction of the double feed electric locomotives to the transport corridors, manifesting in the cargo delivery's time reduction due to reduction of the ready train's standing time at docking stations twice, in comparison with the time during exploitation of the only single-system electric locomotives, and also in increasing of the area's speed of trains in the all polygon of the heavy trains' turnover. The usage of the double feed electric locomotives in areas, which contains different kinds of the current, allows increasing the quality parameters of the traction electric rolling stock's exploitation. There were considered the ways to increase the energy efficiency of the double feed electric locomotives, particularly by applying the electric energy storage unit for connection to the DC link of the electric locomotive's power circuit. The economic assessment of exploitation of the two-systems electric locomotives was carried out.
\end{abstract}

\section{Introduction}

The railway transport development in the world shows its efficiency and being in demand, especially in the field of the high speed passenger transportation. The Russian railways are in stage of the technological development; this is the infrastructure's modernization, the replacement of the old traction rolling stock's series and the perfection of the organization's system of the trains' movement by transition to the polygon's structure of the transportation process' control and the completion of the conversion's process to the vertical integrated control system. There is continuing the development of the electrified railway's polygon, for which as the basic electric traction system is the alternating current's system with the voltage of $25 \mathrm{kWh}$. There is realizing a gradual

\footnotetext{
*Corresponding author: domanov35@gmail.com
} 
replacement of the old locomotives' series for innovative locomotives with the asynchronous traction actuator [1]. In the field of the movement's organization there are implementing an automated systems of the energy-optimal timetable [2-5]. The prospects of the work's perfection of the railway transport in the world tend to the given fields.

One of the foreground directions of the freight turnover in Russia, realized by transport corridors between the ports of the Far East and ports of the North-West, Azov-black sea basin of Russia, are the container transportations, the main way of which lies on the electrified Transsiberian railway with the following integration to the international railway project «Eurasia». The export of the essential materials for the Russian economics - ores, ferrous metal is implementing by main railway artery of the country through the areas of the Middle Siberian move, which include in the structure of the transport corridor of the Kuzbass - Centre with the length of 3824 km (fig. 1).

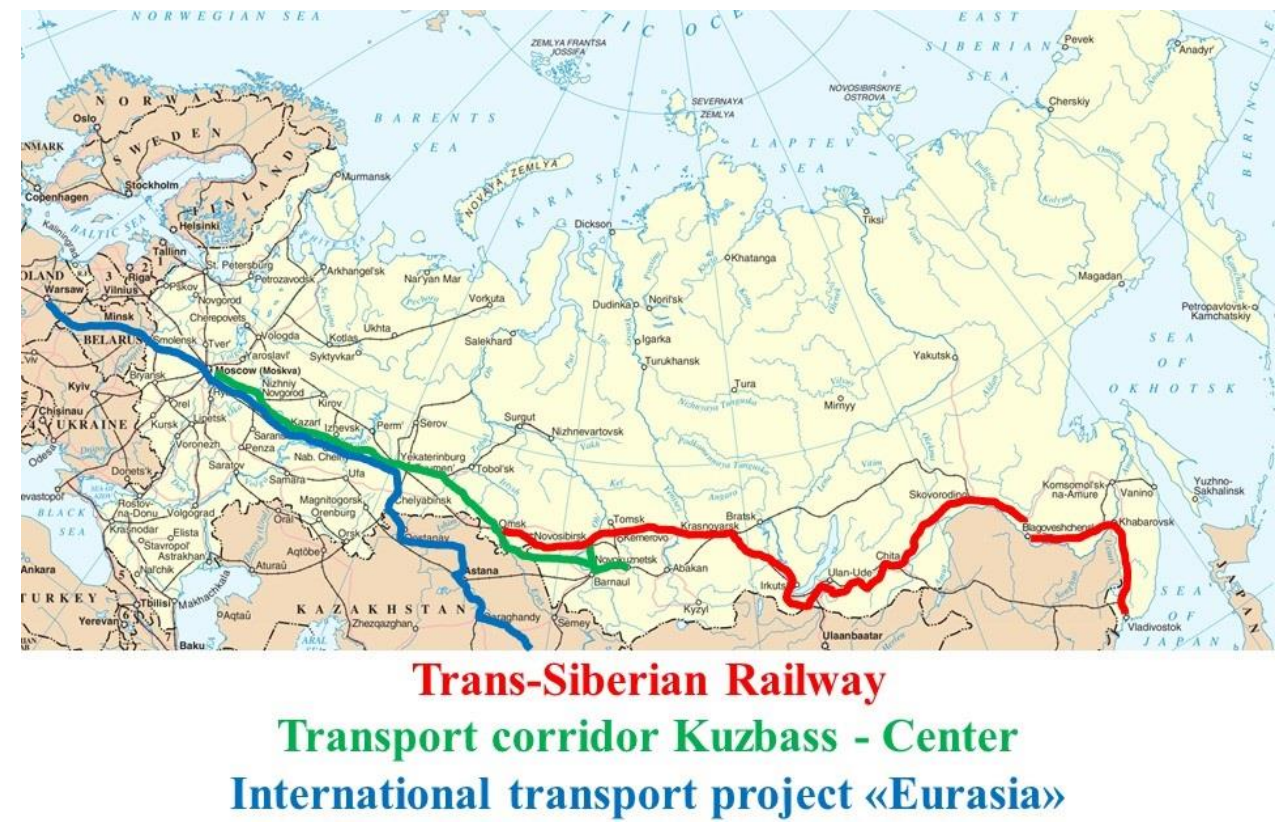

Fig. 1. The transport corridors passing through the territory of Russia.

The realization of the transport corridors for the cargo flow's transit in the direction of East-West is bonded with the cargo delivery's time reduction. For today in RZHD holding there is a need of locomotives for the fast container transportations. On the railway network of Russia there are exploiting the main freight electric locomotive of new DC and AC series, the constructional speed of which is given in the table 1. The specified locomotives' series are intended for the high-weight trains' transportation, and on the areas with the way's mountain profile [6-9], while the average weight of the container train is about 3000 t. The reduction of the train's weight leads to the load's reduction on the upper structure of the railway and in perspective to the speed's increase of the freight transportation with the allowed at present maximum speed of movement for the heavy trains from 80 till $140 \mathrm{~km} / \mathrm{h}$.

Table 1. The constructional speed of the new generation's electric locomotives. 


\begin{tabular}{|c|c|c|}
\hline $\begin{array}{l}\text { The electric locomotive's } \\
\text { series }\end{array}$ & The electric locomotive's name & $\begin{array}{l}\text { The constructional speed, } \\
\mathrm{km} / \mathrm{h}\end{array}$ \\
\hline \multicolumn{3}{|c|}{ The alternating current } \\
\hline 2ES5 & «Scythian» & 120 \\
\hline $2 \mathrm{ES} 5 \mathrm{~K}$ & «Yermak» & 110 \\
\hline \multicolumn{3}{|c|}{ The direct current } \\
\hline $2 \mathrm{ES} 10$ & «Granite» & 120 \\
\hline 2ES4K & «Donchak» & 120 \\
\hline 2ES6 & «Sinara» & 120 \\
\hline
\end{tabular}

The electric rolling stock's energy efficiency depends on many factors, including the train's weight and the way's profile. The specified circumstance leads to the fact, that for the given weight norm more effective is the exploitation of the only one locomotive's series. In a view of the reduction of the train's weight by the container transportations for the energy efficiency' increase of the exploited locomotives of the company "the First locomotive's company» together with the company Bombardier Inc. (the department of the Bombardier Transportation in Russia) on request of the "open society RZHD" for the roads network there was engineered and made the double feed main freight electric locomotive of series 2EV120 «The Duke Vladimir». This locomotive of new generation successfully passed the certificate and и acceptance tests by movement with the speed of $140 \mathrm{~km} / \mathrm{h}$ of the trains with weight about 7000 t. The locomotive of series 2EV120 can work in the DC electric traction systems with the voltage of $3,3 \mathrm{kV}(3,3 \mathrm{VDC})$ and the AC with the voltage of $25 \mathrm{kV}(25 \mathrm{VAC})$. As an advantage of the double feed electric locomotive электровоза of series EV120 towards traditional there is the time reduction on the way by the cargo delivery to the consignor, on account of the time reduction, bonded with the stops for the technological operations for the locomotive's replacement on the current's docking stations. At present on the Russian Railways there are exploiting 27 docking stations, 4 of which are on the areas of the Middle Siberian move. The stops for the traction unit's change of the appropriate current's kind lead to the increase of the trains' downtime on such stations and to the deterioration of the quality parameters of the locomotives' exploitation. The trains' downtime is measured of the train-hours' number, as an example on fig. 2 for the stations of the Middle Siberian move's area there are given the date of the train's downtime in the even and odd directions, bonded with the locomotives' replacement on the docking stations of the current's types.

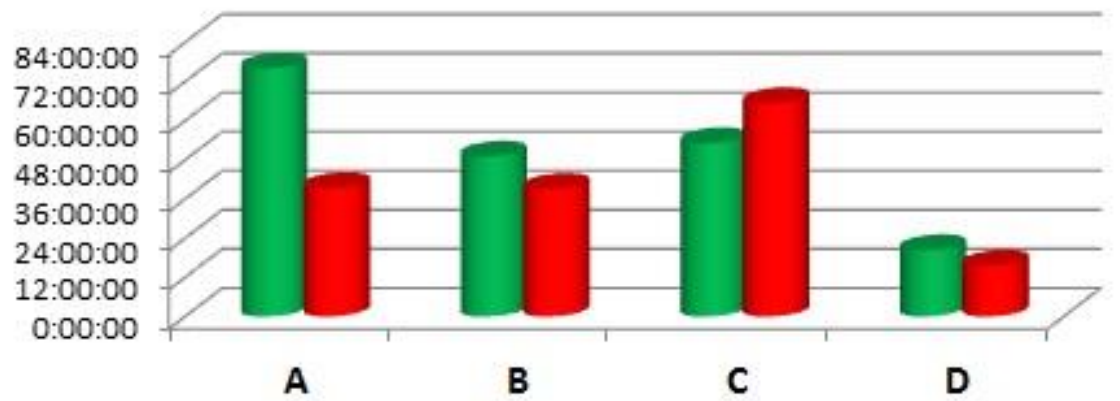

Fig. 2. The total trains' downtime on the docking stations for November 2018.

The performed calculations allow assessing the exploitation's efficiency of the main electric locomotives of series EV120 on the Middle Siberian move's areas. By the calculation's results there were received the prognosis parameters, which influence the parameters of the transportation process:

$\Rightarrow$ the reduction of the trains' downtime; 
$\Rightarrow$ the reduction of the electric locomotives' downtime and the increase of their daily average run;

$\Rightarrow$ the increase of the district speed.

The exploitation's efficiency of the double feed locomotive [10] on the railways of the Transsiberian railway and the Middle Siberian move directly depends on the dockings stations' number of the current's types, located on the circulation's polygons of trains. It is necessary to notice, that the realization of the regenerative braking on the double feed locomotive allow increasing substantially the energy efficiency, especially by using the perspective systems of the electric energy's system of accumulation.

\section{The methods of analysis and perfection of the polygon's technology of the transportation process}

The effect's estimate of the downtime's reduction in the conditions of the exploitation is performing based on the statistical data of the trains' processing on the dockings stations of the current's kinds. The effect's estimate on the work's example on the station A (the Middle Siberian move of the Transsiberian railway), which was performed with the help of the program "Statistic for Windows Release 8.0" [11], allow receiving the following results for the IVth quarter of the year 2018 in relation to the odd and even directions (fig. 3, 4 respectively).

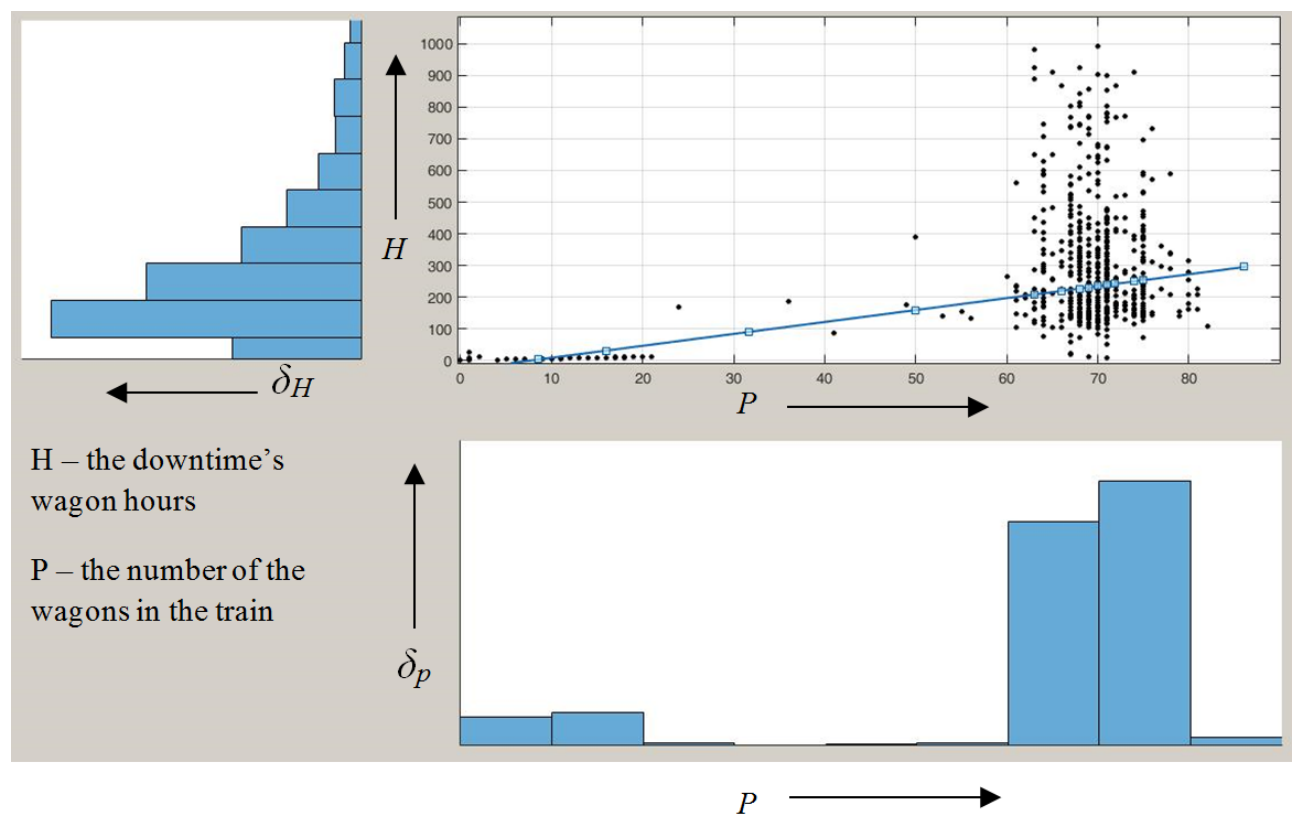

Fig. 3. The wagon's downtime in the even direction. 


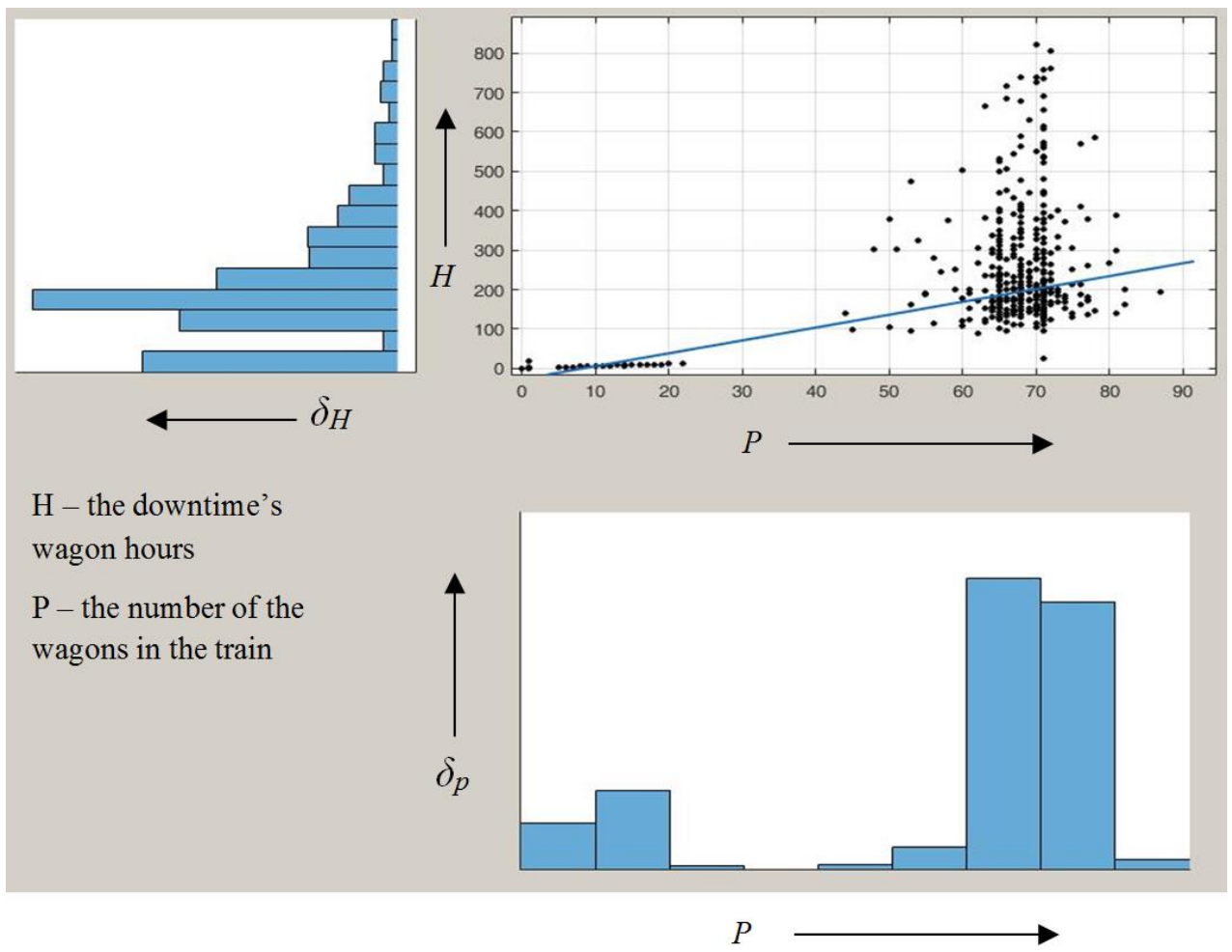

Fig. 4. The wagon's downtime in the odd direction.

The analysis of the received frequency distributions for the movement's amount of 56 pairs of trains per day shows, that the maximal frequency of the observation for the wagon's downtime is observing in the range from 100 up to the 400 wagon hours (the average value from the general downtime is 386 wagon hours) in both movement's directions by the train's structure of $60-80$ wagons. In the specified range of the wagon hours for the train's stopping, which is necessary for the electric locomotive's change for the necessary current's type, the services of the carload economy perform the technological operations: the wagon's inspection, the visual testing of the main breaking's integrity etc. At specified time there are performing the maneuver's operations by the electric locomotives' change and the switching of the point's sections of the contact network's group for the necessary current's type takes about $30 \mathrm{~min}$.

It is necessary to notice, that the train's wagons need the technical inspection every 700 $\mathrm{km}[20]$. For the considering example, the distance from the station of the trains' forming $\mathrm{C}$ to the dockings station's current's types A is $160 \mathrm{~km}$. The distance from the station A to the big junction station, where the train's rearrangement or the locomotive brigades' change is $200 \mathrm{~km}$. Therefore, having in the exploitation the two-system electric locomotive, which capable nonstop to pass the docking's station $\mathbf{A}$, it is possible to increase the traction shoulder of the maintenance of the locomotive brigades for $160 \mathrm{~km}$, and to reduce the total train's downtime on the docking's station.

The electric locomotives' downtime at the turnover point is inseparably bonded with the train's downtime. The electric locomotive's timeout of the departure with the train depends on the area's throughput, from the number of the train's pairs per day and for the docking's station, on which the train can pass en route, is determine by formula: 


$$
t_{\mathrm{oj}}=\frac{\left(c+\left(t_{t r}+d\right) \cdot N_{G}\right) \cdot \varepsilon_{P} \cdot I_{r}}{1440-\left(N_{G} \cdot \varepsilon_{P}+N_{P} \cdot\left(\varepsilon_{G}-1\right)\right) \cdot I_{r}},
$$

where $N_{G}, N_{P}$ - the number of the freight and passenger trains, passing through the docking's station; $c, d$ - coefficients, taking into account the influence of the technical development and the railway line's equipment at train's reception and departure by the transit movement; $t_{t r}$ - the transit passing's time through the station, min; $\varepsilon_{P}, \varepsilon_{G}$ - removal's coefficients of the bandwidth of the freight and passenger trains; $I_{r}$ - inter-train interval of the freight trains in the train's movement's graph, min; 1440 - the minutes' number per day.

One of the factor, influencing the bandwidth of the railway area is the local speed ( $V_{l c}$, $\mathrm{km} / \mathrm{h}$ ) - the average movement's speed of a train on the area, bounded with the big stations, which takes into account the length of the given area $(L, \mathrm{~km})$, the time of train's being on the area $\left(t_{b}, \mathrm{~h}\right)$, the timeout $\left(t_{t m}, \mathrm{~h}\right)$ and the total time of the all stops at following through the area $\left(t_{s t}, \mathrm{u}\right)$, which is determined by the formula [8]:

$$
V_{l c}=\frac{L}{t_{b}+t_{o j}+\sum t_{s t}} .
$$

Knowing the local speed value we can define the daily average locomotive run. It is expressed as a linear run, performed by electric locomotive per day by single movement or as traction unit with the train, without taking into account the electric locomotives, which are doing not train work. The linear run is determined by the formula [9]:

$$
S_{l}=\frac{24}{\frac{1}{V_{l c}}+\frac{t_{o j}}{L}} .
$$

The nonstop passing through the docking's station allows reducing the power consumption on traction trains, which is necessary for the case of the train's acceleration from the staying. The specified circumstance allows increasing the energy efficiency of the transportation process in all.

An important factor by the introduction of the new electric locomotives into the exploitation's technology there is the price of these electric locomotives, taking into account the cost of its life cycle. That is why by the procurement of new electric locomotives it is necessary to define, there is an effect of such electric locomotive on the exploitation's area or not, and what is the maximal price for the payback for the exploitation's period.

For the determination of the maximal cost of the locomotive it is necessary to use the discounted cash flow, which in turn will reflect the cash inflow and outflow during the process of the locomotive's implementation. The money balance for every period is corrected subject to the leading coefficient [19]. As a calculation's value of the limit price we take net present value (NPV) - the accumulated discounted effect for the calculation period период, led to the initial step on the discount norm, from each equation then there will be defined the locomotive's marginal cost. For this we solve the NPV equation, equated the left part to zero, and estimated the all the cash inflow and outflow for a year: 


$$
0=\sum_{t=0}^{T}\left(\Delta C_{a a}+C_{k}+C_{V}+C_{L}+A-Z_{a}\right) \cdot \frac{1}{(1+E)^{t}}-C_{G},
$$

where $\Delta C_{a a}$ - the electric energy's cost, which was saved from the stop's exception of the freight train on the docking's station, rub.; $C_{k}$ - the value of the revenue by the increase of the wagon's downtime of the trough trains, rub.; $C_{L}$ - the value of the revenue by the reduction of the locomotives' downtime and the increasing of the daily average's run, rub.;

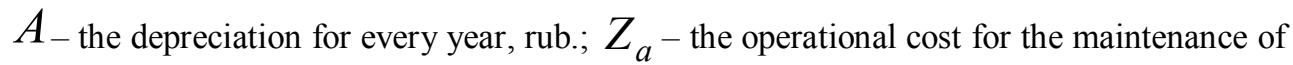
the one double feed freight electric locomotive, rub.; $C_{V}$ - the value of the revenue by the increase of the local speed, rub; $C_{G}-$ the cost of the double feed freight electric locomotive, rub.

\section{Results}

The simulation modeling's results were received for the following source data. It was accepted, that the electric locomotive's service life is 40 years, the discount rate is 0,13 . The calculations are performed for the different electric locomotive's payback periods for the specified marginal cost [12].

With the help of the program Simulink of matrix system MatLab, there was built a simulation model of trains' movement on the Middle Siberian move's areas subject to the integration to the exploitation of the main two-systems electric locomotives of series EV120. As a docking's station by modeling there was taken the above considered station A.

During the simulation modeling of the trains' processing with the exploited locomotives' series and electric locomotive's series EV120 there were received the following results:

$\Rightarrow$ the average time of the trains' downtime of the long trains was reduced twice up to 207,42 wagon hours in the odd and even directions of movement;

$\Rightarrow$ the electric locomotives' downtime on the docking's station was reduced up to the timeout of the departure with the train, equal the average value for the electric locomotives' park of series 2EV120 was $23 \mathrm{~min}$, against to $52 \mathrm{~min}$ by the exploitation of the only single-systems electric locomotives, the daily average locomotive's run was increased from 446 up to $683 \mathrm{~km}$;

$\Rightarrow$ the average value of the local speed of the trains' movement on the examined area was increased from $49,6 \mathrm{~km} / \mathrm{h}$ up to $57,2 \mathrm{~km} / \mathrm{h}$.

As an activity of the energy efficiency's increase of the double feed locomotives is the using of the electric energy storage' systems, allowing increasing the energy parameters of the electric rolling stock and the electric traction system [13-16], particularly, reducing the load of the power equipment and the heating of the current carrying parts in the electric traction system, increasing the work's reliability of the locomotive's equipment, in some cases, increasing the bandwidth and the transportation capacity of the area [17].

The feature of the main two-systems electric locomotive of series EV120 is the presence of the free space on board, intended for the generating set [18], allowing the electric locomotive autonomously to maneuver on the station's traction ways. There exists a technological possibility of the setting instead of the generator of the hybrid electric energy storage. The using of the electric energy storage on board allows aligning the graph of the locomotive's electric load, increasing of the using's efficiency of the regeneration's electric 
energy and the safety of the electric power supply of the asynchronous traction electric engines and the engines of own needs.

The supply of the double feed electric locomotive's asynchronous traction electric engines is performing through the DC link, to which are connected the voltage's DC-AC converters, providing the works of the traction electric engines and the system's engines of own needs [18]. The availability of the DC link allows using the advantages of the electric energy storage' system by the locomotive's work with the DC and AC. The variant of the hybrid electric energy storage's connection in the power circuit of the asynchronous AC electric engines is given on the fig. 5 .

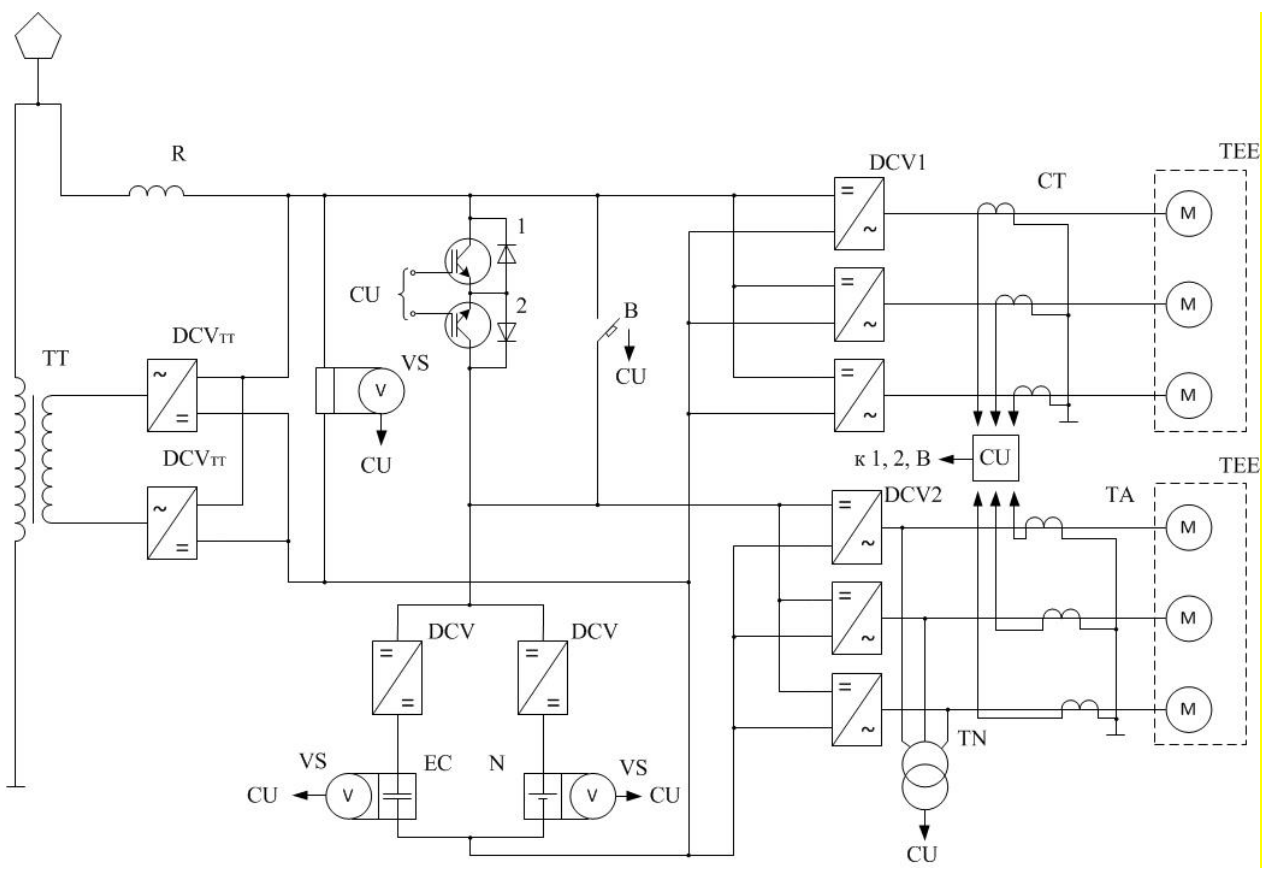

Fig. 5. The energy installation's scheme with the hybrid electric energy storage unit.

The DC link's supply is performing from the contact network through the traction transformer (TT) with the voltage of $25 \mathrm{kV}$ and traction transformers of the AC-DC voltage $\left(\mathrm{DCV}_{\mathrm{TT}}\right)$ or the reactor $(\mathrm{R})$ with the nominal voltage of $3,3 \mathrm{kV}$. The traction transformers of the DC-AC voltage (DCV1-2) implement the supply of the AC asynchronous traction electric engines (TEE) and the asynchronous electric engines of own needs' system (NS), respectively. The voltage's level in the DC line is measured by a voltage sensor (VS), which transfers the dimension's signal to the control unit (CU). As the valves for the connection of the electric energy storage unit to the network introduced the IGBT-modules 1 and 2, which provide the charge and discharge mode of the electric energy storage unit on the TEE and the electric engines of the NS.

The hybrid energy storage connects via the two transformers DCV for the capacitive and the electrochemical module of the electric energy storage, respectively. The charge level of the (EC) and modules (N) is performing using the voltage sensors (VS).

The charge mode of the storage is realizing by the following conditions. By the voltage's increase on the DC line (the measurement is realized by the help of the sensor (VS)) there is analyzed the load's level of the TEE, measured with the help of the current transformers (CT). In the traction mode (the direction of the current's flow to the TEE) by the current's level in the power network is above the level of the charge's setpoint with the 
use of the transformers of the DCV doesn't realize. The transformers' inclusion to the charge mode is performed at achievement of the two conditions - the current's reduction under the setpoint's level and the speed of the load's increase in the power network under the specified of the control unit (CU). The storage's inclusion into the charge mode is performed by means of the supply of the management's positive potential to the valve 1 . The regulation of the charge's current is performed separately in the networks of the electrochemical and capacitive storage. In the generator operating mode of the TEE is performed the charge of the both hybrid storage's modules. The measurement of the current's direction and the change's speed of the voltage's level is realized in the control unit $(\mathrm{CU})$. The measurements of the current and voltage are performed using the current transformers TA TEE of the measuring voltage's transformer NS TN. By creation of the necessary conditions the transformers DCV provide the charge of the both storage's modules. The charge stops by the achievement of the maximal charge's level each module individually. The switch B is intended for the reserve voltage's supply from the DC line for the own needs in case of the work's refusal of the valves 1 and 2 or the control unit (CU).

The charge mode is implemented under condition of the voltage's excess on the modules of the hybrid storage under the given minimal level, for the given values' range для of the traction load and the voltage's reduction on the DC line. For the purpose of the stored energy's use of the storage on board of the electric rolling stock for supply of NS there is providing the storage's shutdown from the supply circuit of TEE by the valve's 2 closing by means of the removal of the control's positive potential with the IGBT-module for the following storage's connection. The storage's discharge to the traction network is performed under condition of the charge of the storage's modules, the achievement of the critical traction load's level and the voltage on the DC link. By the disconnected valves 1 and 2 the storage's discharge is performed for the asynchronous system's engines NS by the reduction of the voltage's level on the DC link to the specified level. The transformers' work of DCV is performed accordingly to the characteristics of the electrochemical and capacitive modules. By achievement of the maximal voltage on the hybrid storage, the device moves to the standby mode or to the discharge mode, depending of the work mode of the electric rolling stock and the energy parameters' values.

The expediency of the implementation of the main double feed electric locomotive of series EV120 with the electric energy storage is performed for the cost's range, depending of the locomotive's complete set and the technical characteristics of the onboard electric energy storage. By the minimal locomotive's cost $(50 \mathrm{mln}$. rub.) the payback is 13 years of the exploitation's beginning and further it grows with the growth of the locomotive's cost (fig. 6). 

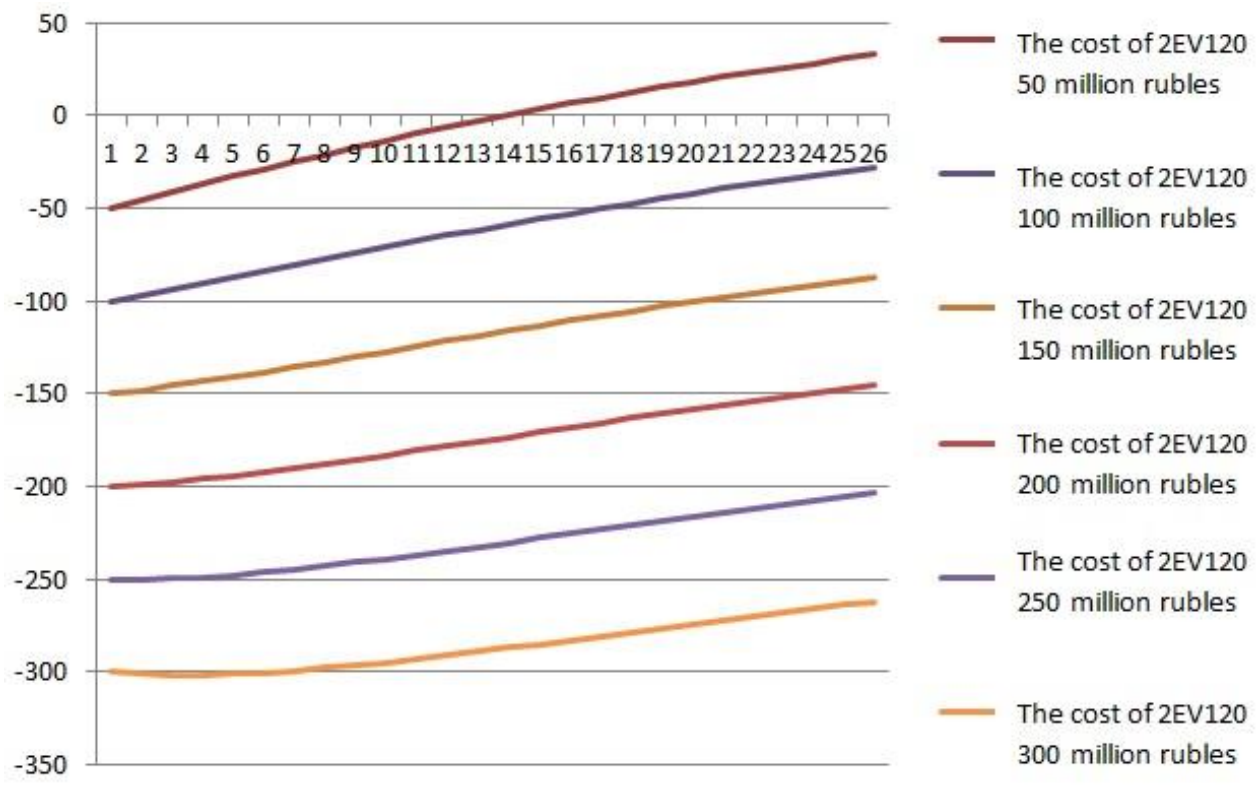

Fig. 6. The graphs of the electric locomotive's payback with different maximal cost in the range from $50 \mathrm{mln}$. rub. up to $300 \mathrm{mln}$. rub.

\section{Conclusions}

The reduction of the trains and electric locomotives' downtime on the docking's stations of the current's kinds on account of the double feed electric locomotives' use allow increasing the daily average run of the electric locomotives and the local speed positively affects the graph of the trains' movement. The use in the double feed electric locomotive's energy installation of the hybrid electric energy storage allow increasing the electric locomotive's energy efficiency, the reliability of the own needs' electric power supply and providing the graph's smoothing of the train's electric load. The offered scheme of the electric locomotive's energy installation is intended for the realization of the driven charge and discharge's modes of the hybrid storage in depending of the voltage's level on the locomotive's engines, the change's speed of the capacity of the traction electric engines and own needs, the capacity transferring to the traction network, separately for theдля electrochemical and capacitive module of the electric energy storage, the control's opportunity of the direction of the storage's capacity in the charge mode on the SN of the electric rolling stock or the total load together with the load of the TEE.

\section{Acknowledgement}

Prepared with the support of the Russian Foundation of the fundamental initiatives under the grant № 17-20-01148 ofi_m_RZHD/18.

\section{References}

1. S. Istomin, Electric locomotives 4, 186 - 189 (2015)

2. V.Yu. Kiryakin, The railway transport 6, 18-24 (2014) 
3. V.Yu. Kiryakin, Bulletin of the joint scientific council open society "RZHD” 1, 16-20 (2014)

4. L.A. Muginshteyn, The railway transport 3, 13 - 19 (2015)

5. O.V. Gatelyuk, Proceedings of the TRANS-Siberian railway 1(21), 59 - 69 (2015)

6. V.T. Cheremisin, Bulletin of the Rostov State Transport University 2, $118-128$ (2017)

7. V.L. Nezevak, The transport of the Urals 4(55), 65 - 70 (2017)

8. V.L. Nezevak, Bulletin of the Volga region's transport 6(66), 34-44 (2017)

9. V.T. Cheremisin, Proceedings of Tomsk Polytechnic University, Engineering of georesources 326(10), $54-64$ (2017)

10. K.I. Domanov, MATEC Web of Conferences 239, 218-227 (2018)

11. A. A. Khalafyan, Statistic 6. The statistical analysis of data (Binom, Moscow, 2007)

12. S.V. Pokrovsky, Locomotives 10, 2-3 (2015)

13. The method of the cost's determination of the life cycle and the limit cost of the rolling stock and the complex technical systems of the railway transport, The order 2459 (RZHD, 2007)

14. V.L. Nezevak, The world of transport 16(2), 84 - 94 (2018)

15. V.L. Nezevak, International Journal of Advanced Railway 1(2), 53 - 56 (2013)

16. A.P. Shatokhin, Materials of the 2nd All-Russian scientific-practical conference with international participation, 162 - 168 (2014)

17. S.N. Chizhma, A.A. Kuznetsov, D.V. Pashkov, A.A. Lavrukhin, A.G. Malyutin, A.S. Okishev, A.P. Shatokhin, The device of the modes' control of the DC traction substation's work, Pat. 159971 of Russian Federation (Omsk State Transport University, Omsk, 2016)

18. V. T. Cheremisin, The scientific monograph (2018)

19. The double feed electric locomotive's, user manual of series EV120, part 2 (2016)

20. The economic and technical parameters as of 30.12.2018, The traction directorate's letter 8051/CT (RZHD, 2019)

21. About $O$ norms of the overhaul runs of the railway rolling stock, exploiting on the infrastructure of the open society "RZHD", The order 1651 (RZHD, 2016) 